\title{
Electronic structure origin of conductivity and oxygen reduction activity changes in low-level Cr-substituted ( $\mathrm{La}, \mathrm{Sr}) \mathrm{MnO}_{3}$
}

\author{
George Tsekouras, ${ }^{1, a), b)}$ Florent Boudoire, ${ }^{1}$ Banabir Pal, ${ }^{2}$ Martin Vondráček, ${ }^{3}$ \\ Kevin C. Prince, ${ }^{4}$ D. D. Sarma, ${ }^{2}$ and Artur Braun ${ }^{1}$ \\ ${ }^{1}$ Laboratory for High Performance Ceramics, Swiss Federal Laboratories for Materials Science \\ and Technology, Dübendorf, Switzerland \\ ${ }^{2}$ Solid State and Structural Chemistry Unit, Indian Institute of Science, Bangalore, India \\ ${ }^{3}$ Institute of Physics, Academy of Sciences of the Czech Republic, Prague, Czech Republic \\ ${ }^{4}$ Materials Science Beamline, Elettra Synchrotron, Trieste, Italy
}

(Received 22 May 2015; accepted 3 September 2015; published online 18 September 2015)

\begin{abstract}
The electronic structure of the $\left(\mathrm{La}_{0.8} \mathrm{Sr}_{0.2}\right)_{0.98} \mathrm{Mn}_{1-x} \mathrm{Cr}_{x} \mathrm{O}_{3}$ model series $(x=0,0.05$, or 0.1$)$ was measured using soft $\mathrm{X}$-ray synchrotron radiation at room and elevated temperature. O K-edge nearedge X-ray absorption fine structure (NEXAFS) spectra showed that low-level chromium substitution of $(\mathrm{La}, \mathrm{Sr}) \mathrm{MnO}_{3}$ resulted in lowered hybridisation between $\mathrm{O} 2 \mathrm{p}$ orbitals and $\mathrm{M} 3 \mathrm{~d}$ and $\mathrm{M} 4 \mathrm{sp}$ valance orbitals. $\mathrm{Mn}_{3}$-edge resonant photoemission spectroscopy measurements indicated lowered Mn 3d-O 2p hybridisation with chromium substitution. Deconvolution of O K-edge NEXAFS spectra took into account the effects of exchange and crystal field splitting and included a novel approach whereby the pre-peak region was described using the nominally filled $\mathrm{t}_{2 \mathrm{~g}} \uparrow$ state. $10 \%$ chromium substitution resulted in a $0.17 \mathrm{eV}$ lowering in the energy of the $t_{2 \mathrm{~g}} \uparrow$ state, which appears to provide an explanation for the $0.15 \mathrm{eV}$ rise in activation energy for the oxygen reduction reaction, while decreased overlap between hybrid O 2p-Mn 3d states was in qualitative agreement with lowered electronic conductivity. An orbital-level understanding of the thermodynamically predicted solid oxide fuel cell cathode poisoning mechanism involving low-level chromium substitution on the B-site of (La, Sr) $\mathrm{MnO}_{3}$ is presented. ( 2015 AIP Publishing LLC. [http://dx.doi.org/10.1063/1.4931033]
\end{abstract}

\section{INTRODUCTION}

Solid oxide fuel cells (SOFCs) are promising for the distributable and efficient conversion of chemical energy (e.g., from natural gas, biogas, and liquefied petroleum gas) to electrical energy and could thus play an important role in lowering greenhouse gas emissions. However, SOFCs can suffer from a number of stability problems, including chromium poisoning of the widely employed cathode based on the perovskite oxide $(\mathrm{La}, \mathrm{Sr}) \mathrm{MnO}_{3}$ by chromium-containing metallic alloy interconnects.

Chromium poisoning of ( $\mathrm{La}, \mathrm{Sr}) \mathrm{MnO}_{3}$-based SOFC cathodes includes the initial formation of $\mathrm{Cr}_{2} \mathrm{O}_{3(\mathrm{~s})}$ on the interconnect surface, volatilisation of $\mathrm{Cr}_{2} \mathrm{O}_{3(\mathrm{~s})}$ to $\mathrm{CrO}_{3(\mathrm{~g})}$ and $\mathrm{CrO}_{2}(\mathrm{OH})_{2(\mathrm{~g})}$, deposition of chromium species at triple-phaseboundary active sites, and reaction of chromium species with $(\mathrm{La}, \mathrm{Sr}) \mathrm{MnO}_{3}$ to form $(\mathrm{Cr}, \mathrm{Mn})_{3} \mathrm{O}_{4}$. In addition, the thermodynamically predicted low-level substitution of chromium on the B-site of $(\mathrm{La}, \mathrm{Sr}) \mathrm{MnO}_{3}{ }^{1}$ could be a source of cathode degradation underlying more overt and well-known chromium poisoning mechanisms, particularly on the ca. $40000 \mathrm{~h}$ time scale of SOFC system lifetime requirements.

\footnotetext{
a) Current address: Australian Research Council Centre of Excellence for Electromaterials Science, University of Wollongong, Wollongong, Australia.

b) Author to whom correspondence should be addressed. Electronic mail: georget@uow.edu.au. Tel.: +61 242215677.
}

We previously measured significant decreases in electronic conductivity and electrochemical oxygen reduction activity in air between 650 and $850{ }^{\circ} \mathrm{C}$ upon low-level chromium substitution of $(\mathrm{La}, \mathrm{Sr}) \mathrm{MnO}_{3} .{ }^{2}$ In seeking to further explain such changes with respect to their orbitallevel origin, we present here the electronic structure of the $\left(\mathrm{La}_{0.8} \mathrm{Sr}_{0.2}\right)_{0.98} \mathrm{Mn}_{1-x} \mathrm{Cr}_{x} \mathrm{O}_{3}$ series $(x=0,0.05$, or 0.1$)$, which models the thermodynamically predicted low-level substitution of chromium on the B-site of $(\mathrm{La}, \mathrm{Sr}) \mathrm{MnO}_{3}$. $\mathrm{O} \mathrm{K}$-edge and $\mathrm{Mn} \mathrm{L}$-edge near-edge X-ray absorption fine structure (NEXAFS) spectroscopies and $\mathrm{Mn} \mathrm{L}_{3}$-edge resonant photoemission spectroscopy (RPES) at room and elevated temperature were performed, representing the first time that soft X-ray synchrotron radiation has been used to gain insight into the chromium poisoning of $(\mathrm{La}, \mathrm{Sr}) \mathrm{MnO}_{3}$-based SOFC cathodes. Lowered hybridisation between metal $3 \mathrm{~d}$ and oxygen $2 \mathrm{p}$ orbitals and reduced overlap between hybrid orbitals upon low-level chromium substitution on the B-site of $\left(\mathrm{La}_{0.8} \mathrm{Sr}_{0.2}\right)_{0.98} \mathrm{MnO}_{3}$ are demonstrated, consistent with previously shown decreases in electronic conductivity and electrochemical oxygen reduction activity.

\section{EXPERIMENTAL}

Details regarding the synthesis and structural characterisation of the $\left(\mathrm{La}_{0.8} \mathrm{Sr}_{0.2}\right)_{0.98} \mathrm{Mn}_{1-x} \mathrm{Cr}_{x} \mathrm{O}_{3}$ model series are provided elsewhere. ${ }^{2}$ In brief, compositions were prepared by solid state synthesis using stoichiometric amounts of $\mathrm{La}_{2} \mathrm{O}_{3}$, 
$\mathrm{SrCO}_{3}, \mathrm{Cr}_{2} \mathrm{O}_{3}$, and $\mathrm{Mn}_{2} \mathrm{O}_{3}$. Room temperature powder X-ray diffractometry (XRD) revealed that all compositions were isostructural single phase perovskites with respect to the analysis, while observed Bragg peak splitting was consistent with rhombohedral crystal symmetry.

Samples for soft X-ray spectroscopy were prepared by initial uniaxial pressing of $\left(\mathrm{La}_{0.8} \mathrm{Sr}_{0.2}\right)_{0.98} \mathrm{Mn}_{1-x} \mathrm{Cr}_{x} \mathrm{O}_{3}$ powders into circular pellets under $150 \mathrm{MPa}$ load followed by firing at $1300{ }^{\circ} \mathrm{C}$ in air for $12 \mathrm{~h}$, which yielded ca. $1.5 \mathrm{~mm}$ thick samples with $78 \%-84 \%$ relative density. These pellet samples were subsequently cut using a water-cooled diamond saw into ca. $10 \times 6 \mathrm{~mm}$ rectangular pieces suitable for the tantalum sample holder at the Materials Science Beamline, ELETTRA synchrotron light source, Trieste, Italy. The sample holder included a Type $\mathrm{K}$ chromel-alumel thermocouple that was placed in contact with the underside of the sample, and separated from it by a piece of tantalum foil to avoid any unwanted chemical reaction. The heating terminals and thermocouple were electrically isolated from each other and from the base plate by ceramic spacers.

Samples were inserted into the main chamber via a fast entry load lock. Sample surfaces were prepared in the main chamber by $\mathrm{Ar}^{+}$sputtering for $1 \mathrm{~h}$ under $2 \times 10^{-6}$ mbar Ar pressure and $1 \mathrm{keV}$ energy, followed by annealing at $300{ }^{\circ} \mathrm{C}$ for $10 \mathrm{~min}$. A plane grating monochromator ${ }^{3}$ delivered incident light, which was incident at an angle of $30^{\circ}$ on the sample surface. Photoelectrons were measured normal to the sample surface using a SPECS Phoibos 150 hemispherical energy analyser. A gold mesh was used to measure the incoming photon flux. The base pressure of the main chamber during measurements was in the low $10^{-10}$ mbar range. During elevated temperature measurements, the direct resistive heating supplied to the sample was chopped using control software developed in-house and achieved with alternating $100 \mathrm{~ms}$ heating and measurement cycles.

La 3d, Sr 3d, and Mn 2p X-ray photoemission spectroscopy (XPS) was measured using $980 \mathrm{eV}$ incident photon energy and analysed using CasaXPS v 2.3.16 software. The area under experimentally measured spectral peaks, with calculated Shirley backgrounds subtracted, was corrected using relative sensitivity factors and was used to calculate $(\mathrm{La}+\mathrm{Sr}) / \mathrm{Mn}$ ratios. Inelastic-mean-free-path (IMFP) values for XPS measurements ranging between ca. 0.5 and $1.6 \mathrm{~nm}$ were calculated using National Institute of Standards and Technology Inelastic-Mean-Free-Path Database v 1.2 software, ${ }^{4}$ wherein the Tanuma, Powell, and Penn (TPP-2M) model was used. Considering that sampling depth is defined as 3.IMFP. $\cos \theta,{ }^{5}$ where a zero $\theta$ angle corresponds to the measurement of photoelectrons normal to the sample surface, the IMFP values for XPS measurements of ca. 0.5$1.6 \mathrm{~nm}$ corresponded to sampling depths of ca. 1.5-4.8 nm. Considering that such sampling depths are several times larger compared to the XRD-derived pseudocubic cell parameter $\left(\mathrm{a}_{\mathrm{p}}\right)$ values of ca. $0.39 \mathrm{~nm}$ for the $\left(\mathrm{La}_{0.8} \mathrm{Sr}_{0.2}\right)_{0.98} \mathrm{Mn}_{1-x} \mathrm{Cr}_{x} \mathrm{O}_{3}$ model series, the XPS performed here was somewhat reflective of bulk properties, in addition to surface properties.

$\mathrm{O}$ K-edge and Mn L-edge NEXAFS spectra were measured by monitoring the emitted O KLL and Mn LMM Auger electron signals, respectively, and deconvoluted using
winXAS v 3.2 software. ${ }^{6}$ IMFP values for NEXAFS measurements of ca. 1.2-1.3 nm were calculated, corresponding to sampling depths of ca. 3.6-3.9 nm. $\mathrm{Mn} \mathrm{L}_{3}$-edge RPES spectra were measured with incident photon energies ranging between 638 and $644.5 \mathrm{eV}$. An IMFP value of ca. $1.3 \mathrm{~nm}$ was calculated, corresponding to a sampling depth of ca. $3.9 \mathrm{~nm}$. Fityk v 0.9.8 software $^{7}$ was used to calculate Shirley backgrounds for Mn $\mathrm{L}_{3}$-edge RPES spectra prior to deconvolution using winXAS v 3.2 software. All measurements were performed in Auger yield mode.

\section{RESULTS AND DISCUSSION}

\section{A. O K-EDGE near-edge X-ray absorption fine structure}

O K-edge NEXAFS spectroscopy measures unoccupied hybrid oxygen $2 \mathrm{p}$-metal $3 \mathrm{~d}$ states, thereby reflecting the extent of covalency between $\mathrm{O} 2 \mathrm{p}$ and $\mathrm{M} 3 \mathrm{~d}$ orbitals. ${ }^{8-11}$ Another way to think about this is to consider that no $\mathrm{O}$ K-edge NEXAFS signal would be expected for purely ionic oxides. ${ }^{12}$ Fig. 1 presents the room temperature $\mathrm{O}$ K-edge NEXAFS spectra of the $x=0,0.05$, and 0.1 members of the $\left(\mathrm{La}_{0.8} \mathrm{Sr}_{0.2}\right)_{0.98} \mathrm{Mn}_{1-x} \mathrm{Cr}_{x} \mathrm{O}_{3}$ model series. The spectra are characterised by 3 main features, which may be attributed, with increasing photon energy, to hybridisation between $\mathrm{O} 2 \mathrm{p}$ orbitals and M 3d, La 5d/Sr 4d, and M 4sp orbitals, ${ }^{9}$ where M denotes $\mathrm{Mn}$ and $\mathrm{Cr}$.

The intensity data in Fig. 1 has been adjusted by normalisation and a specific type of correction. Normalisation to the La $5 \mathrm{~d} / \mathrm{Sr} 4 \mathrm{~d}$ feature accounted for any differences in signal collection between samples brought about by experimental variables, such as sample alignment. The specific correction applied here involved multiplication by the $(\mathrm{La}+\mathrm{Sr}) / \mathrm{Mn}$ ratios calculated from $\mathrm{La} 3 \mathrm{~d}, \mathrm{Sr} 3 \mathrm{~d}$, and $\mathrm{Mn} 2 \mathrm{p}$ XPS data (not shown). $(\mathrm{La}+\mathrm{Sr}) / \mathrm{Mn}$ ratios of ca. 1.8 were calculated for

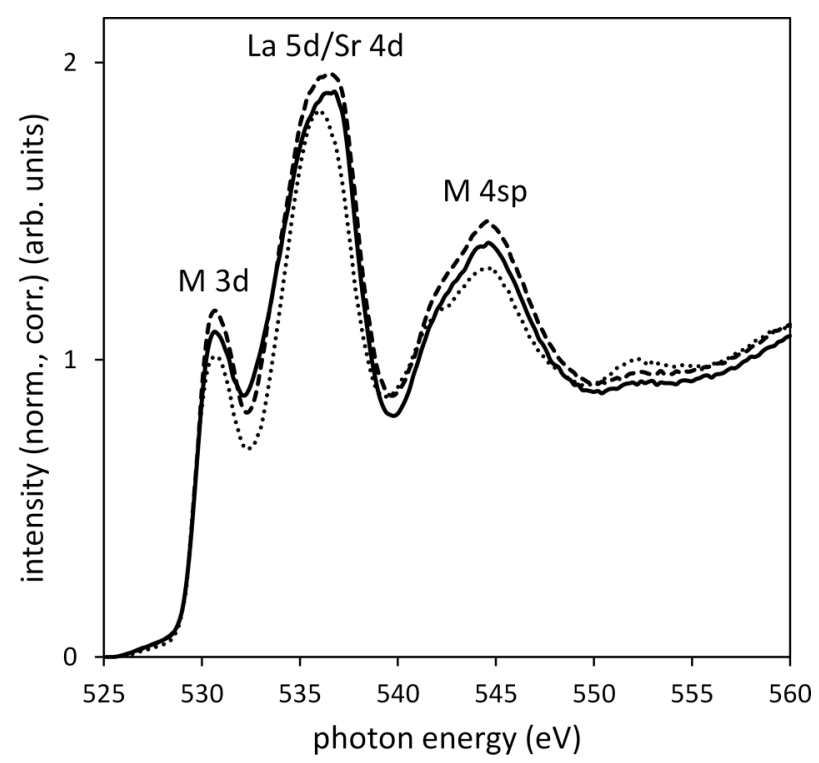

FIG. 1. Room temperature, normalised, and corrected $\mathrm{O} \mathrm{K}$-edge near-edge $\mathrm{X}$-ray absorption fine structure spectra of $\left(\mathrm{La}_{0.8} \mathrm{Sr}_{0.2}\right)_{0.98} \mathrm{Mn}_{1-x} \mathrm{Cr}_{x} \mathrm{O}_{3}$ model series compositions $(--) x=0(-) x=0.05(\bullet \bullet \bullet) x=0.1$. 
all members of the $\left(\mathrm{La}_{0.8} \mathrm{Sr}_{0.2}\right)_{0.98} \mathrm{Mn}_{1-x} \mathrm{Cr}_{x} \mathrm{O}_{3}$ model series, which were significantly higher compared to the $(\mathrm{La}+\mathrm{Sr}) / \mathrm{Mn}$ ratios calculated according to the nominal stoichiometry of compositions, thus reflecting the well-known phenomenon of surface A-site enrichment in perovskite oxides. ${ }^{13-15}$ XPS measurements also revealed the phenomenon of strontium segregation, with $\mathrm{Sr} /(\mathrm{La}+\mathrm{Sr})$ ratios of ca. 0.5 calculated for all compositions, compared to the nominal $\mathrm{Sr} /(\mathrm{La}+\mathrm{Sr})$ ratio of 0.2. Surface A-site enrichment obscured signals originating from unoccupied hybrid $\mathrm{M} 3 \mathrm{~d}-\mathrm{O} 2 \mathrm{p}$ and $\mathrm{M} 4 \mathrm{sp}-\mathrm{O} 2 \mathrm{p}$ orbitals; however, this was corrected for by multiplying the intensity data in Fig. 1 by $(\mathrm{La}+\mathrm{Sr}) / \mathrm{Mn}$ ratios.

The results in Fig. 1 reveal that low-level chromium substitution of $(\mathrm{La}, \mathrm{Sr}) \mathrm{MnO}_{3}$ resulted in lowered hybridisation between $\mathrm{O} 2 \mathrm{p}$ orbitals and $\mathrm{M} 3 \mathrm{~d}$ and $\mathrm{M}$ 4sp valance orbitals. Considering that electronic conduction within $(\mathrm{La}, \mathrm{Sr}) \mathrm{MnO}_{3}$ takes place via a small polaron hopping mechanism involving electron transfer between two $\mathrm{Mn}$ cations through the bridging oxygen anion, ${ }^{16}$ the decrease in oxygen-metal hybridisation helps to explain the previously reported drop in room temperature electronic conductivity from $131 \mathrm{~S} \mathrm{~cm}^{-1}$ for $\left(\mathrm{La}_{0.8} \mathrm{Sr}_{0.2}\right)_{0.98} \mathrm{MnO}_{3}$ to 19 $\mathrm{S} \mathrm{cm}{ }^{-1}$ for $\left(\mathrm{La}_{0.8} \mathrm{Sr}_{0.2}\right)_{0.98} \mathrm{Mn}_{0.95} \mathrm{Cr}_{0.05} \mathrm{O}_{3}$ and $8 \mathrm{~S} \mathrm{~cm}^{-1}$ for $\left(\mathrm{La}_{0.8} \mathrm{Sr}_{0.2}\right)_{0.98} \mathrm{Mn}_{0.9} \mathrm{Cr}_{0.1} \mathrm{O}_{3}{ }^{2}$

In order to extract additional information from O K-edge NEXAFS spectra, we deconvoluted spectra by fitting Gaussian functions representing a multitude of hybrid orbitals, plus an arctan step function. To this end, we first consider the effects of exchange splitting $\left(\Delta_{\mathrm{ex}}\right)$ and octahedral field splitting $\left(\Delta_{\mathrm{O}}\right)$ on the $3 \mathrm{~d}$ orbitals of $\mathrm{Mn}^{3+}\left(3 \mathrm{~d}^{4}\right)$ and $\mathrm{Mn}^{4+}\left(3 \mathrm{~d}^{3}\right)$ within (La,Sr) $\mathrm{MnO}_{3}$ (Fig. 2). Note that for the approach to fitting described below, we have assumed that the $\mathrm{Mn}^{4+}$ in $(\mathrm{La}, \mathrm{Sr}) \mathrm{MnO}_{3}$ exists only as $3 \mathrm{~d}^{3}$, while previous soft X-ray absorption spectroscopy studies of $\mathrm{Mn}^{4+}$-containing compounds have pointed out that $\mathrm{Mn}^{4+}$ exists as a mixture of $3 \mathrm{~d}^{3}$ and $3 \mathrm{~d}^{4} \underline{\mathrm{L}},{ }^{9,17}$ where $\underline{\mathrm{L}}$ denotes a hole on the ligand. However, we demonstrate below that the assumption of a pure $3 \mathrm{~d}^{3}$ configuration for $\mathrm{Mn}^{4+}$ is acceptable for the purposes of this analysis.

Fig. 2 provides an important reference for the deconvolution of the $\mathrm{O} 2 \mathrm{p}-\mathrm{Mn} 3 \mathrm{~d}$ feature in O K-edge NEXAFS spectra. The only slightly larger magnitude of $\Delta_{\mathrm{ex}}$ compared to $\Delta_{\mathrm{O}}$ leads to the superposition of $\mathrm{e}_{\mathrm{g}} \uparrow$ and $\mathrm{t}_{2 \mathrm{~g}} \downarrow$ orbitals, ${ }^{9,18-20}$ which makes it difficult to separate them experimentally. This led us to model both $\mathrm{e}_{\mathrm{g}} \uparrow$ and $\mathrm{t}_{2 \mathrm{~g}} \downarrow$ orbitals using one Gaussian function only. A novelty here compared to previous studies was the description of the pre-peak region of $\mathrm{O}$ K-edge NEXAFS spectra using the $\mathrm{t}_{2 \mathrm{~g}} \uparrow$ hybrid orbital. Considering that the NEXAFS technique measures empty states, the mere ability to observe any signal originating from this state may be explained by the semiconducting nature of the studied materials. That is, at any point in time, a proportion of electrons belonging to the nominally filled $t_{2 \mathrm{~g}} \uparrow$ hybrid orbital are thermally excited, even at room temperature, to higher energy hybrid orbitals, thus giving rise to a modest $\mathrm{t}_{2 \mathrm{~g}} \uparrow$ signal. The $\mathrm{O} 2 \mathrm{p}-\mathrm{Mn} 3 \mathrm{~d}$ feature of O K-edge NEXAFS spectra was, therefore, deconvoluted using 3 Gaussian functions corresponding, with increasing energy, to $\mathrm{t}_{2 \mathrm{~g}} \uparrow,\left(\mathrm{e}_{\mathrm{g}} \uparrow+\mathrm{t}_{2 \mathrm{~g}} \downarrow\right)$, and $\mathrm{e}_{\mathrm{g}} \downarrow$ hybrid orbitals.
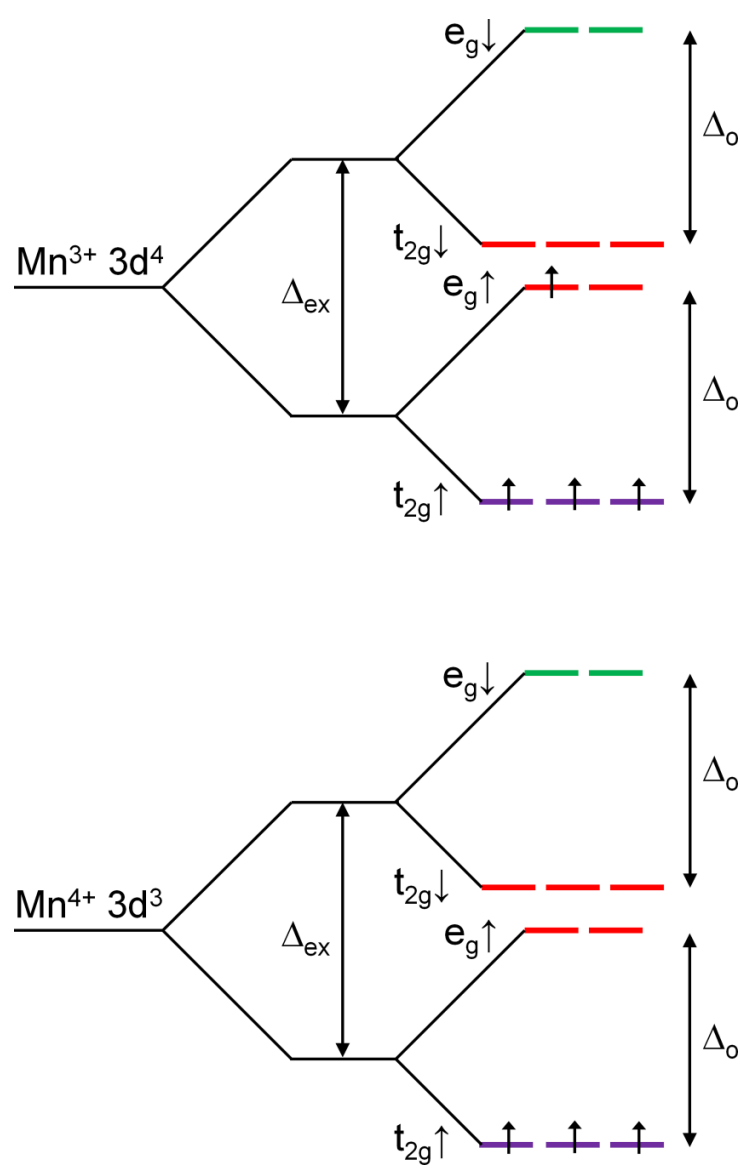

FIG. 2. Schematic representation of effects of exchange splitting $\left(\Delta_{\mathrm{ex}}\right)$ and octahedral field splitting $\left(\Delta_{\mathrm{O}}\right)$ on the $3 \mathrm{~d}$ orbitals of $\mathrm{Mn}^{3+}\left(3 \mathrm{~d}^{4}\right)$ and $\mathrm{Mn}^{4+}\left(3 \mathrm{~d}^{3}\right)$ within $(\mathrm{La}, \mathrm{Sr}) \mathrm{MnO}_{3}$. Since $\Delta_{\mathrm{ex}}$ is only slightly larger than $\Delta_{\mathrm{O}}$, superposition of $\mathrm{e}_{\mathrm{g}} \uparrow$ and $\mathrm{t}_{2 \mathrm{~g}} \downarrow$ orbitals occurs. Effects of Jahn-Teller distortion in $\mathrm{Mn}^{3+}$ omitted for clarity.

To sensibly deconvolute $\mathrm{O}$ K-edge NEXAFS spectra, we found that it was crucial to fix the $\left(\mathrm{e}_{\mathrm{g}} \uparrow+\mathrm{t}_{2 \mathrm{~g}} \downarrow\right)$ : $\mathrm{e}_{\mathrm{g}} \downarrow$ integrated intensity ratio during fitting. Ratios were calculated based on counting the number of empty states schematically represented in Fig. 2. In addition, it was necessary to take into account the fact that in octahedral complexes the $e_{g}$ orbitals point directly towards the $\mathrm{O} 2 \mathrm{p}$ orbitals and are therefore more hybridised compared to the $t_{2 \mathrm{~g}}$ orbitals. Assuming that hybridisation between $\mathrm{t}_{2 \mathrm{~g}}$ and $\mathrm{O} 2 \mathrm{p}$ orbitals is about half of that between $\mathrm{e}_{\mathrm{g}}$ and $\mathrm{O} 2 \mathrm{p}$ orbitals, ${ }^{8} \mathrm{a}\left(\mathrm{e}_{\mathrm{g}} \uparrow+\mathrm{t}_{2 \mathrm{~g}} \downarrow\right)$ : $\mathrm{e}_{\mathrm{g}} \downarrow$ ratio of $\left(1+\frac{3}{2}\right): 2(=1.25)$ was determined for $\mathrm{Mn}^{3+}$ and a ratio of $\left(2+\frac{3}{2}\right): 2(=1.75)$ was determined for $\mathrm{Mn}^{4+}$. Taking into account the relative nominal concentrations of $\mathrm{Mn}^{3+}$ and $\mathrm{Mn}^{4+}$, according to $\mathrm{Sr}^{2+}$ substitution for $\mathrm{La}^{3+}$ and A-site deficiency, the $\left(\mathrm{e}_{\mathrm{g}} \uparrow+\mathrm{t}_{2 \mathrm{~g}} \downarrow\right)$ : $\mathrm{e}_{\mathrm{g}} \downarrow$ ratio for the $x=0$ member of the $\left(\mathrm{La}_{0.8} \mathrm{Sr}_{0.2}\right)_{0.98} \mathrm{Mn}_{1-x} \mathrm{Cr}_{x} \mathrm{O}_{3}$ model series, for example, is 1.378 . This assumes a $3 \mathrm{~d}^{3}$ configuration for $\mathrm{Mn}^{4+}$, while an analogous ratio of 1.314 is obtained assuming an equal weighting of $3 \mathrm{~d}^{3}$ and $3 \mathrm{~d}^{4} \mathrm{~L}$ configurations for $\mathrm{Mn}^{4+}$. We consider that such a modest variation in the $\left(\mathrm{e}_{\mathrm{g}} \uparrow+\mathrm{t}_{2 \mathrm{~g}} \downarrow\right)$ : $\mathrm{e}_{\mathrm{g}} \downarrow$ ratio did not affect the analysis. Moreover, in the absence of known $3 \mathrm{~d}^{3}$ and $3 \mathrm{~d}^{4} \underline{\mathrm{L}}$ configuration weightings, it is impossible to precisely calculate $\left(\mathrm{e}_{\mathrm{g}} \uparrow+\mathrm{t}_{2 \mathrm{~g}} \downarrow\right)$ : $\mathrm{e}_{\mathrm{g}} \downarrow$ ratios. Finally, calculated ratios varied only slightly with $x$. For example, $\left(\mathrm{e}_{\mathrm{g}} \uparrow\right.$ 

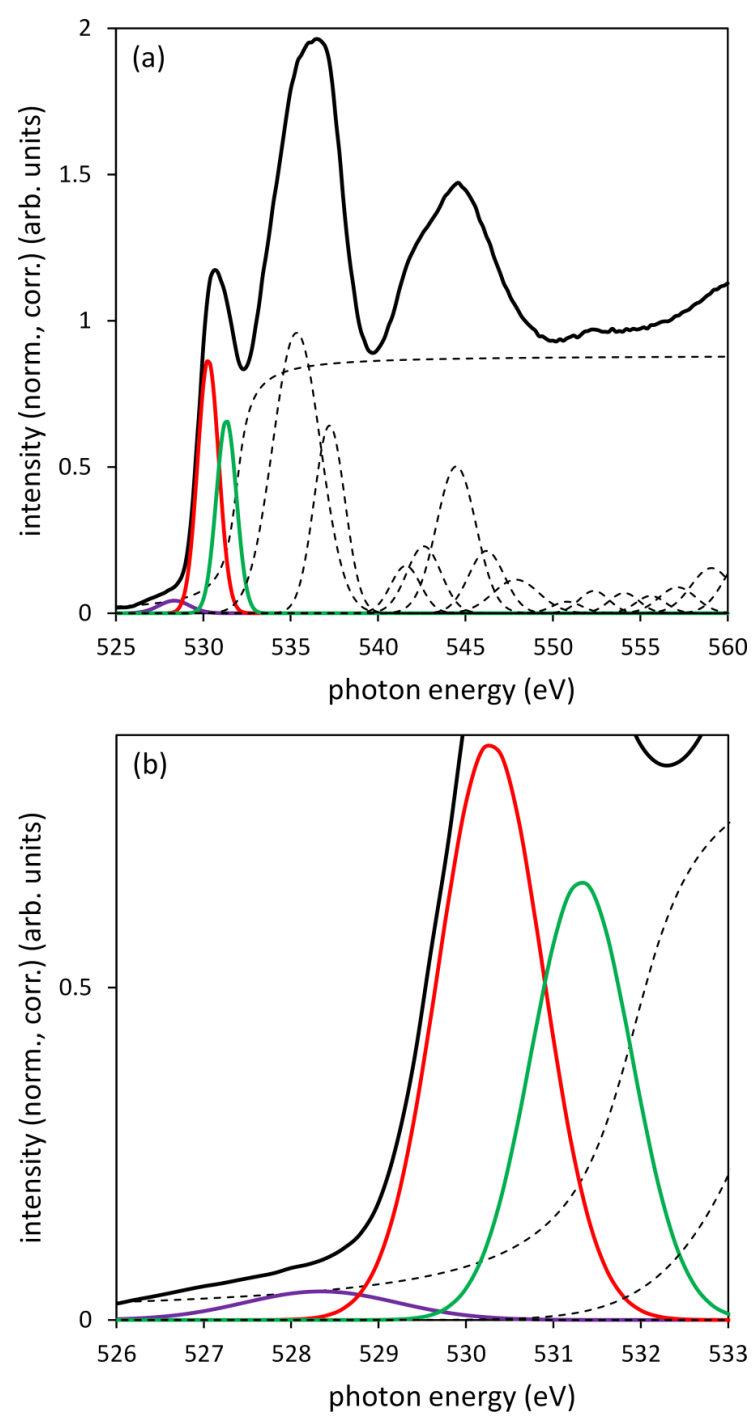

FIG. 3. Room temperature, normalised, corrected, and deconvoluted $\mathrm{O}$ K-edge near-edge $\mathrm{X}$-ray absorption fine structure spectrum of $\left(\mathrm{La}_{0.8} \mathrm{Sr}_{0.2}\right)_{0.98} \mathrm{MnO}_{3}$ (a) complete experimental photon energy range, (b) focus on O 2p-Mn 3d feature. Solid black line: measured. Violet line: $\mathrm{t}_{2 \mathrm{~g}} \uparrow$. Red line: $\left(\mathrm{e}_{\mathrm{g}} \uparrow+\mathrm{t}_{2 \mathrm{~g}} \downarrow\right)$. Green line: $\mathrm{e}_{\mathrm{g}} \downarrow$. (-- - ) arctan step function and multiple other Gaussian functions.

$\left.+\mathrm{t}_{2 \mathrm{~g}} \downarrow\right): \mathrm{e}_{\mathrm{g}} \downarrow$ ratio $=1.392$ for $\left(\mathrm{La}_{0.8} \mathrm{Sr}_{0.2}\right)_{0.98} \mathrm{Mn}_{0.9} \mathrm{Cr}_{0.1} \mathrm{O}_{3}$, assuming a $3 \mathrm{~d}^{3}$ configuration for $\mathrm{Mn}^{4+}$.

Fig. 3 presents the deconvoluted, room temperature, normalised, and corrected O K-edge NEXAFS spectrum of $\left(\mathrm{La}_{0.8} \mathrm{Sr}_{0.2}\right)_{0.98} \mathrm{MnO}_{3}$, including colour coding of the hybrid orbitals that make up the $\mathrm{O} 2 \mathrm{p}-\mathrm{Mn} 3 \mathrm{~d}$ feature. The sum of Gaussian and arctan step functions was indistinguishable from the experimentally measured spectrum. Analogous treatment of the O K-edge NEXAFS spectrum for the $x=0.1$ member of the $\left(\mathrm{La}_{0.8} \mathrm{Sr}_{0.2}\right)_{0.98} \mathrm{Mn}_{1-x} \mathrm{Cr}_{x} \mathrm{O}_{3}$ model series revealed that chromium substitution significantly influenced the position, intensity, and overlap of hybrid orbitals. The relationship between such influences and materials properties is detailed below.

Regarding the position of hybrid orbitals deconvoluted from room temperature O K-edge NEXAFS spectra, $10 \%$ chromium substitution on the B-site of $\left(\mathrm{La}_{0.8} \mathrm{Sr}_{0.2}\right)_{0.98} \mathrm{MnO}_{3}$ resulted in a $0.17 \mathrm{eV}$ lowering of the $\mathrm{t}_{2 \mathrm{~g}} \uparrow$ hybrid orbital energy. Taking inspiration from Jung and Tuller, ${ }^{21}$ this is

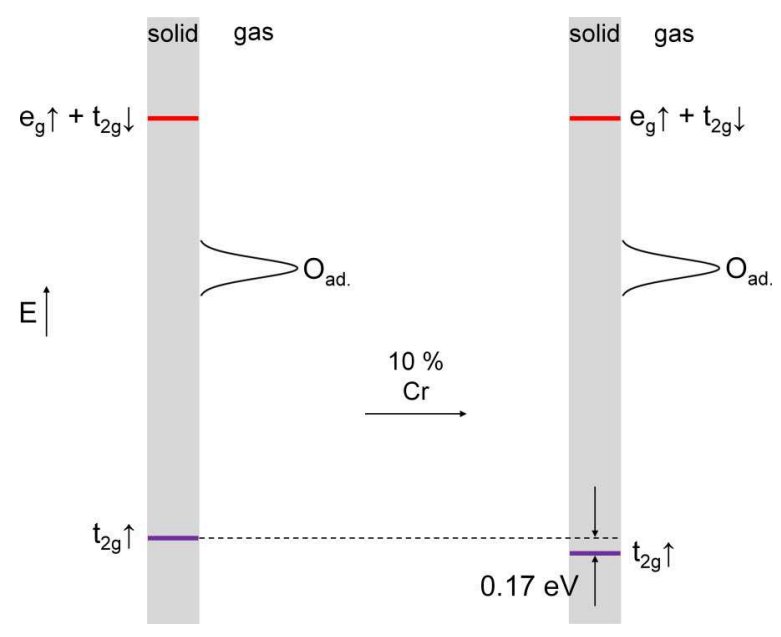

FIG. 4. Schematic of $\mathrm{t}_{2 \mathrm{~g}} \uparrow$ and $\left(\mathrm{e}_{\mathrm{g}} \uparrow+\mathrm{t}_{2 \mathrm{~g}} \downarrow\right)$ hybrid O $2 \mathrm{p}-\mathrm{Mn} 3 \mathrm{~d}$ orbital energies at room temperature from deconvoluted $\mathrm{O} \mathrm{K}$-edge nearedge X-ray absorption fine structure spectra of $\left(\mathrm{La}_{0.8} \mathrm{Sr}_{0.2}\right)_{0.98} \mathrm{MnO}_{3}$ and $\left(\mathrm{La}_{0.8} \mathrm{Sr}_{0.2}\right)_{0.98} \mathrm{Mn}_{0.9} \mathrm{Cr}_{0.1} \mathrm{O}_{3}$. Adsorbed oxygen at the solid/gas interface is also illustrated.

represented schematically in Fig. 4, which also illustrates adsorbed oxygen at the solid/gas interface, which in turn is relevant to the operation of a SOFC cathode. Assuming that observed differences in electronic structure at room temperature may be indicative of differences in electronic structure at SOFC operating temperatures, the $0.17 \mathrm{eV}$ lowering of the $t_{2 g} \uparrow$ hybrid orbital energy appears to provide an explanation for the previously demonstrated $0.15 \mathrm{eV}$ increase in oxygen reduction reaction (ORR) activation energy $\left(E_{a}\right)$, determined over the temperature range $650-850{ }^{\circ} \mathrm{C}$, from $1.39 \mathrm{eV}$ on $\left(\mathrm{La}_{0.8} \mathrm{Sr}_{0.2}\right)_{0.98} \mathrm{MnO}_{3} / 8 \mathrm{~mol} \%$ yttria-stabilised zirconia (YSZ) to $1.54 \mathrm{eV}$ on $\left(\mathrm{La}_{0.8} \mathrm{Sr}_{0.2}\right)_{0.98} \mathrm{Mn}_{0.9} \mathrm{Cr}_{0.1} \mathrm{O}_{3} / \mathrm{YSZ}^{2}$ This apparent relationship between electronic band structure and ORR kinetics suggests that electron transfer across the oxide surface to adsorbed oxygen is the rate determining step. This is further supported by the fact that the $E_{a}$ for the ORR on $\left(\mathrm{La}_{0.8} \mathrm{Sr}_{0.2}\right)_{0.98} \mathrm{MnO}_{3} / \mathrm{YSZ}(1.39 \mathrm{eV})$ is significantly higher compared to the $\mathrm{E}_{\mathrm{a}}$ for electronic conduction in $\left(\mathrm{La}_{0.8} \mathrm{Sr}_{0.2}\right)_{0.98} \mathrm{MnO}_{3}\left(\mathrm{E}_{\mathrm{a}}\left(\sigma_{\mathrm{el}}\right)=0.105 \mathrm{eV}\right)^{2}$ and the $\mathrm{E}_{\mathrm{a}}$ for ionic conduction in $\operatorname{YSZ}\left(\mathrm{E}_{\mathrm{a}}\left(\sigma_{\mathrm{ion}}\right)=0.85 \mathrm{eV}\right) .^{22}$

Going beyond the position of hybrid orbitals deconvoluted from room temperature $\mathrm{O}$ K-edge NEXAFS spectra, their intensity and overlap offer an enhanced understanding of electronic conductivity changes brought about by heating and low-level chromium substitution. Fig. 5 overlays the Gaussian functions representing $\mathrm{t}_{2 \mathrm{~g}} \uparrow$ orbitals within $\left(\mathrm{La}_{0.8} \mathrm{Sr}_{0.2}\right)_{0.98} \mathrm{MnO}_{3}$ at room and elevated temperature, and within $\left(\mathrm{La}_{0.8} \mathrm{Sr}_{0.2}\right)_{0.98} \mathrm{Mn}_{0.9} \mathrm{Cr}_{0.1} \mathrm{O}_{3}$ at elevated temperature. Considering first the effects of heating on $\left(\mathrm{La}_{0.8} \mathrm{Sr}_{0.2}\right)_{0.98} \mathrm{MnO}_{3}$, the $\mathrm{t}_{2 \mathrm{~g}} \uparrow$ orbital increases in intensity and broadens, thus raising overlap with nearby $\mathrm{e}_{\mathrm{g}} \uparrow, \mathrm{t}_{2 \mathrm{~g}} \downarrow$, and $\mathrm{e}_{\mathrm{g}} \downarrow$ orbitals (not shown). Such an increase in the overlap between hybrid $\mathrm{O} 2 \mathrm{p}-\mathrm{Mn} 3 \mathrm{~d}$ orbitals may provide a qualitative explanation for the increase, via enhanced double-exchange, ${ }^{23}$ in the electronic conductivity of $\left(\mathrm{La}_{0.8} \mathrm{Sr}_{0.2}\right)_{0.98} \mathrm{MnO}_{3}$ from $131 \mathrm{~S}$ $\mathrm{cm}^{-1}$ at room temperature to $174 \mathrm{~S} \mathrm{~cm}^{-1}$ at $850{ }^{\circ} \mathrm{C}$. Upon $10 \%$ chromium substitution on the B-site of $\left(\mathrm{La}_{0.8} \mathrm{Sr}_{0.2}\right)_{0.98} \mathrm{MnO}_{3}$, the intensity of the $t_{2 g} \uparrow$ orbital decreased, while this orbital 


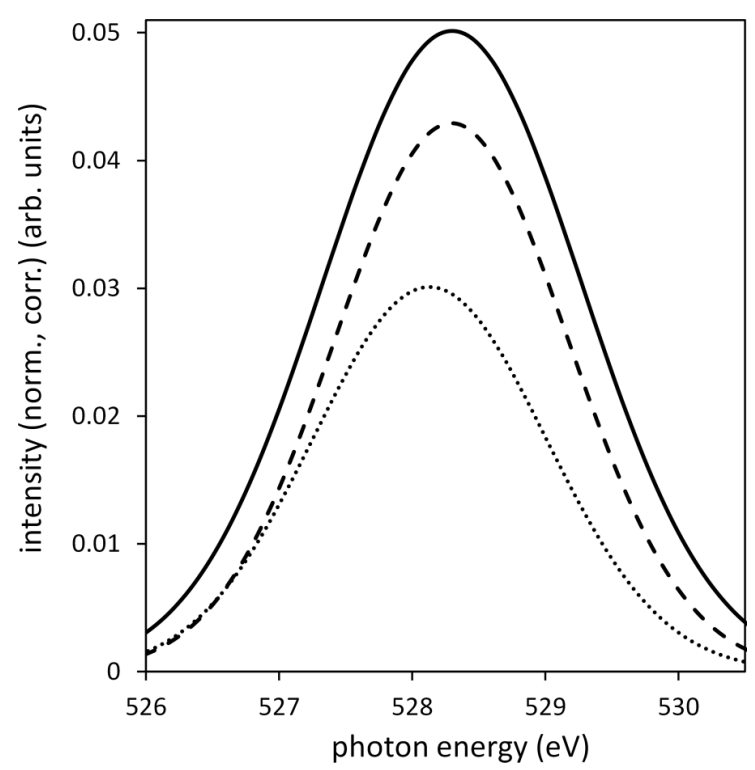

FIG. 5. Deconvoluted $t_{2 g} \uparrow$ orbital from normalised and corrected $\mathrm{O}$ K-edge near-edge $\mathrm{X}$-ray absorption fine structure spectra of (---) $\left(\mathrm{La}_{0.8} \mathrm{Sr}_{0.2}\right)_{0.98} \mathrm{MnO}_{3}$ at $25^{\circ} \mathrm{C},(-)\left(\mathrm{La}_{0.8} \mathrm{Sr}_{0.2}\right)_{0.98} \mathrm{MnO}_{3}$ at $300{ }^{\circ} \mathrm{C}$, and $(\bullet \bullet \bullet)$ $\left(\mathrm{La}_{0.8} \mathrm{Sr}_{0.2}\right)_{0.98} \mathrm{Mn}_{0.9} \mathrm{Cr}_{0.1} \mathrm{O}_{3}$ at $300{ }^{\circ} \mathrm{C}$.

also shifted to a lower energy by $0.17 \mathrm{eV}$ as described above. The combined effect of $t_{2 g} \uparrow$ orbital intensity and position changes led to a decrease in overlap between hybrid O $2 \mathrm{p}-\mathrm{Mn} 3 \mathrm{~d}$ orbitals. This provides a partial qualitative explanation for the decrease in room temperature electronic conductivity from $131 \mathrm{~S} \mathrm{~cm}^{-1}$ for $\left(\mathrm{La}_{0.8} \mathrm{Sr}_{0.2}\right)_{0.98} \mathrm{MnO}_{3}$ to $8 \mathrm{~S}$ $\mathrm{cm}^{-1}$ for $\left(\mathrm{La}_{0.8} \mathrm{Sr}_{0.2}\right)_{0.98} \mathrm{Mn}_{0.9} \mathrm{Cr}_{0.1} \mathrm{O}_{3}$, in addition to the core explanation regarding the decrease in the number of available small polaron hopping sites.

\section{B. Mn L-edge near-edge X-ray absorption fine structure}

In order to further probe the electronic structure of the $\left(\mathrm{La}_{0.8} \mathrm{Sr}_{0.2}\right)_{0.98} \mathrm{Mn}_{1-x} \mathrm{Cr}_{x} \mathrm{O}_{3}$ model series, Mn L-edge NEXAFS spectroscopy was performed. Fig. 6 shows the room temperature $\mathrm{Mn}$ L-edge NEXAFS spectrum of $\left(\mathrm{La}_{0.8} \mathrm{Sr}_{0.2}\right)_{0.98} \mathrm{MnO}_{3}$, the results of deconvolution (including arctan function steps), and a superimposed orbital energy diagram combining the effects of spin-orbit splitting of the Mn 2p core-hole and octahedral field splitting, which explains the origin of fitted peak functions. A sensible overall fit could only be achieved by employing Gaussian functions for the $\mathrm{L}_{3}$ $t_{2 g}, L_{2} t_{2 g}$, and $L_{2} e_{g}$ orbitals and a pseudo-Voigt function for the $\mathrm{L}_{3} \mathrm{e}_{\mathrm{g}}$ orbital. By applying the same fitting approach to the $\mathrm{Mn}$ L-edge NEXAFS spectra of all $\left(\mathrm{La}_{0.8} \mathrm{Sr}_{0.2}\right)_{0.98} \mathrm{Mn}_{1-x} \mathrm{Cr}_{x} \mathrm{O}_{3}$ model series compositions, spin-orbit and octahedral field splitting values in the order of $10.6 \mathrm{eV}$ and $1.7 \mathrm{eV}$ were obtained, respectively. The results of Mn L-edge NEXAFS spectroscopy allowed for the selection of photon energies resonant with the $\mathrm{L}_{3}$ absorption peak for RPES measurements.

\section{C. $M n L_{3}$-EDGE resonant photoelectron spectroscopy}

Fig. 7(a) shows large resonance effects in the room temperature $\mathrm{MnL}_{3}$-edge RPES spectra of $\left(\mathrm{La}_{0.8} \mathrm{Sr}_{0.2}\right)_{0.98} \mathrm{MnO}_{3}$

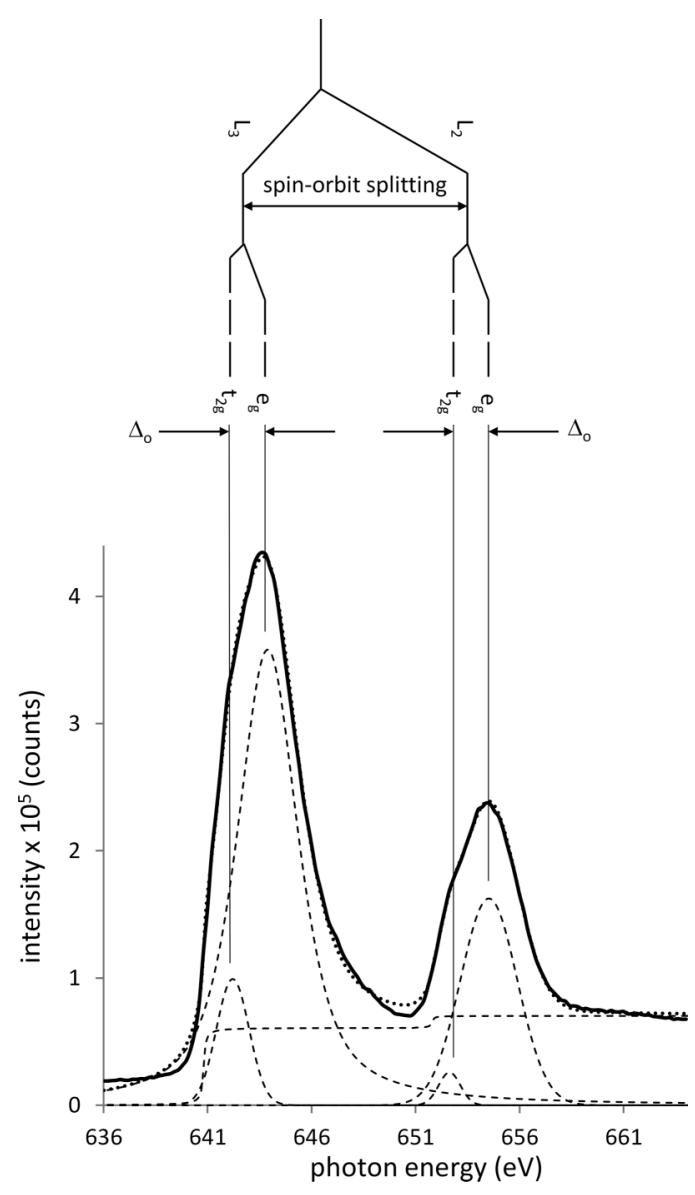

FIG. 6. (-) Room temperature Mn L-edge near-edge X-ray absorption fine

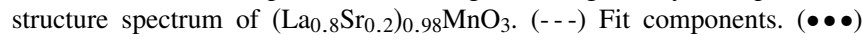
Sum of fit components. Mn 3d energy level diagram showing effects of spin-orbit and octahedral field $\left(\Delta_{\mathrm{O}}\right)$ splitting superimposed to indicate origin of fitted peak functions.

as the incident photon energy was swept through the $\mathrm{L}_{3}$ absorption peak of the corresponding Mn L-edge NEXAFS spectrum (inset). Based on literature concerning the RPES analysis of perovskite oxides, ${ }^{24-26}$ the features in Fig. 7(a) were assigned to $\mathrm{Mn} 3 \mathrm{~d} \mathrm{e}_{\mathrm{g}}$ and $\mathrm{t}_{2 \mathrm{~g}}$ orbitals (1.0-4.2 eV), hybrid O 2p-Mn 3d orbitals (4.2-9.4 eV), and to a satellite feature (above $9.4 \mathrm{eV}$ ). Fig. 7(b) shows the room temperature, on-resonance $\mathrm{Mn} \mathrm{L}_{3}-$ edge RPES spectrum of $\left(\mathrm{La}_{0.8} \mathrm{Sr}_{0.2}\right)_{0.98} \mathrm{MnO}_{3}$ measured using $643.5 \mathrm{eV}$ incident photon energy and its deconvolution into a Shirley background and Gaussian functions corresponding to $\mathrm{Mn} 3 \mathrm{~d} \mathrm{e}_{\mathrm{g}}$ (at $2.1 \mathrm{eV}$ ) and $\mathrm{t}_{2 \mathrm{~g}}$ (at $3.7 \mathrm{eV}$ ) orbitals, hybrid O 2p-Mn 3d orbitals ("C" at $4.7 \mathrm{eV}$ and "D" at $7.7 \mathrm{eV}$ ), and a satellite feature (at $10.6 \mathrm{eV}$ ). The sum of the Shirley background and Gaussian functions was indistinguishable from the experimentally measured spectrum.

To illustrate the effects of heating and chromium substitution, Fig. 8 shows the normalised, on-resonance $\mathrm{Mn} \mathrm{L}_{3}$-edge RPES spectra of $\left(\mathrm{La}_{0.8} \mathrm{Sr}_{0.2}\right)_{0.98} \mathrm{MnO}_{3}$ at room and elevated temperature, and $\left(\mathrm{La}_{0.8} \mathrm{Sr}_{0.2}\right)_{0.98} \mathrm{Mn}_{0.9} \mathrm{Cr}_{0.1} \mathrm{O}_{3}$ at elevated temperature, all measured using $643.5 \mathrm{eV}$ incident photon energy. Simple observation of Fig. 8 reveals that heating $\left(\mathrm{La}_{0.8} \mathrm{Sr}_{0.2}\right)_{0.98} \mathrm{MnO}_{3}$ resulted in increased signal intensity in the part of the spectrum attributed to $\mathrm{O} 2 \mathrm{p}-\mathrm{Mn}$ 3d hybrid orbitals $\mathrm{C}$ and $\mathrm{D}$, in comparison to $\mathrm{Mn} 3 \mathrm{~d}$ 

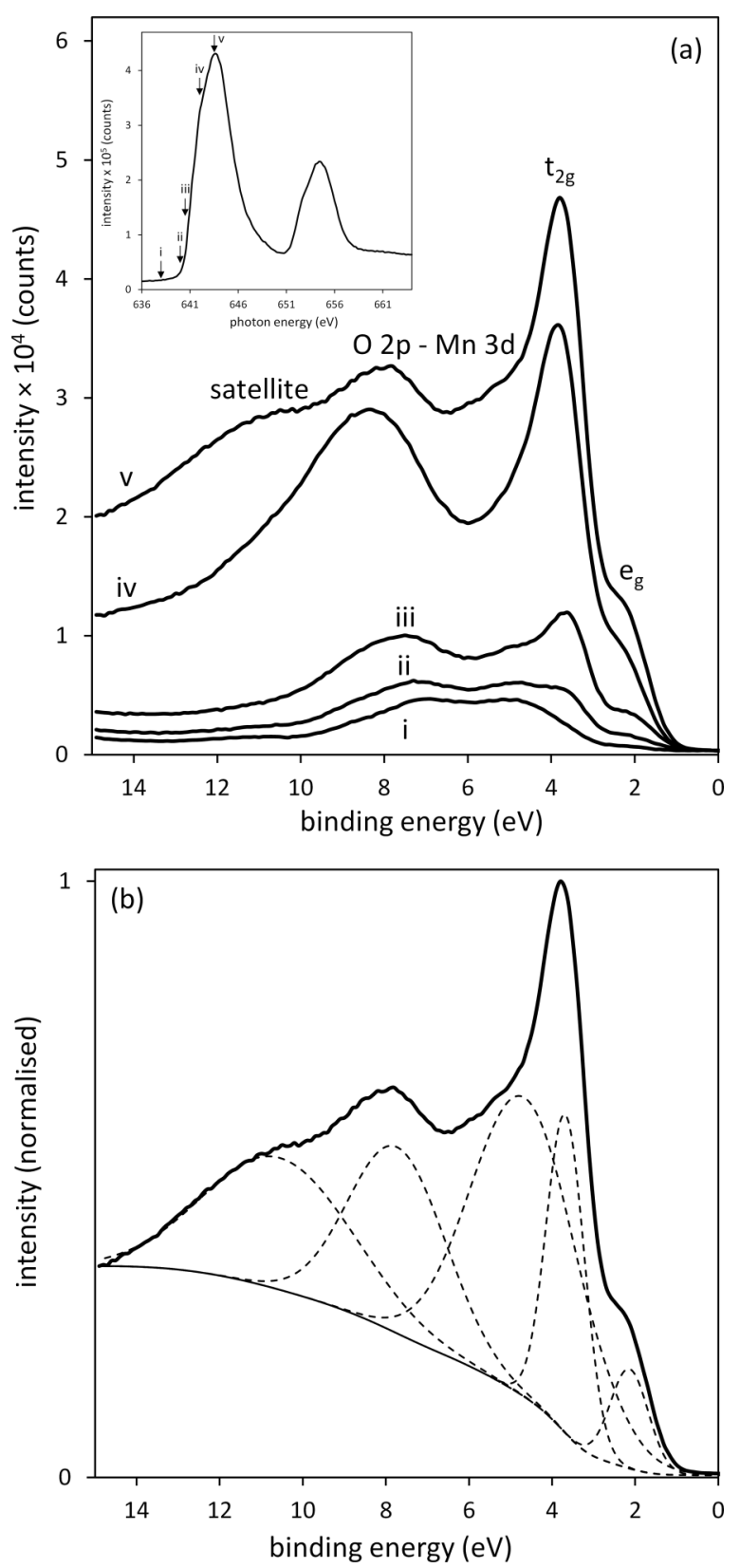

FIG. 7. (a) Room temperature $\mathrm{Mn} \mathrm{L}_{3}$-edge resonant photoelectron spectra of $\left(\mathrm{La}_{0.8} \mathrm{Sr}_{0.2}\right)_{0.98} \mathrm{MnO}_{3}$ as incident photon energy increased through (i) $638.0 \mathrm{eV}$, (ii) $640.0 \mathrm{eV}$, (iii) $640.5 \mathrm{eV}$, (iv) $642.0 \mathrm{eV}$, and (v) $643.5 \mathrm{eV}$. Inset: room temperature $\mathrm{Mn} \mathrm{L}$-edge near-edge $\mathrm{X}$-ray absorption fine structure spectrum of $\left(\mathrm{La}_{0.8} \mathrm{Sr}_{0.2}\right)_{0.98} \mathrm{MnO}_{3}$ with incident photon energies used in (a) indicated by arrows. (b) Deconvolution of room temperature on-resonance $\mathrm{Mn} \mathrm{L}_{3}$-edge resonant photoelectron spectrum of $\left(\mathrm{La}_{0.8} \mathrm{Sr}_{0.2}\right)_{0.98} \mathrm{MnO}_{3}$ with a Shirley background and Gaussians corresponding to $\mathrm{Mn} 3 \mathrm{~d} \mathrm{e}$ (at $2.1 \mathrm{eV}$ ) and $\mathrm{t}_{2 \mathrm{~g}}($ at $3.7 \mathrm{eV}$ ) orbitals, hybrid $\mathrm{O} 2 \mathrm{p}-\mathrm{Mn} 3 \mathrm{~d}$ orbitals (at $4.7 \mathrm{eV}$ and $7.7 \mathrm{eV}$ ), and a satellite feature $(10.6 \mathrm{eV})$; incident photon energy $=643.5 \mathrm{eV}$.

$\mathrm{e}_{\mathrm{g}}$ and $\mathrm{t}_{2 \mathrm{~g}}$ orbitals. That is, $\mathrm{O} 2 \mathrm{p}-\mathrm{Mn} 3 \mathrm{~d}$ hybridisation within $\left(\mathrm{La}_{0.8} \mathrm{Sr}_{0.2}\right)_{0.98} \mathrm{MnO}_{3}$ increased upon heating. This was likely a manifestation of the general tendency of crystals to attain higher symmetry when heated, which translates in the case of perovskite manganites to a Mn-O-Mn angle approaching $180^{\circ}$, increased overlap between $\mathrm{O} 2 \mathrm{p}$ and $\mathrm{Mn}$ $3 \mathrm{~d}$ orbitals, and enhanced double-exchange. ${ }^{23}$ In order to quantify the increase in hybridisation with heating, we may define the ratio $(\mathrm{C}+\mathrm{D}) /\left(\mathrm{e}_{\mathrm{g}}+\mathrm{t}_{2 \mathrm{~g}}\right)$ using integrated intensities.

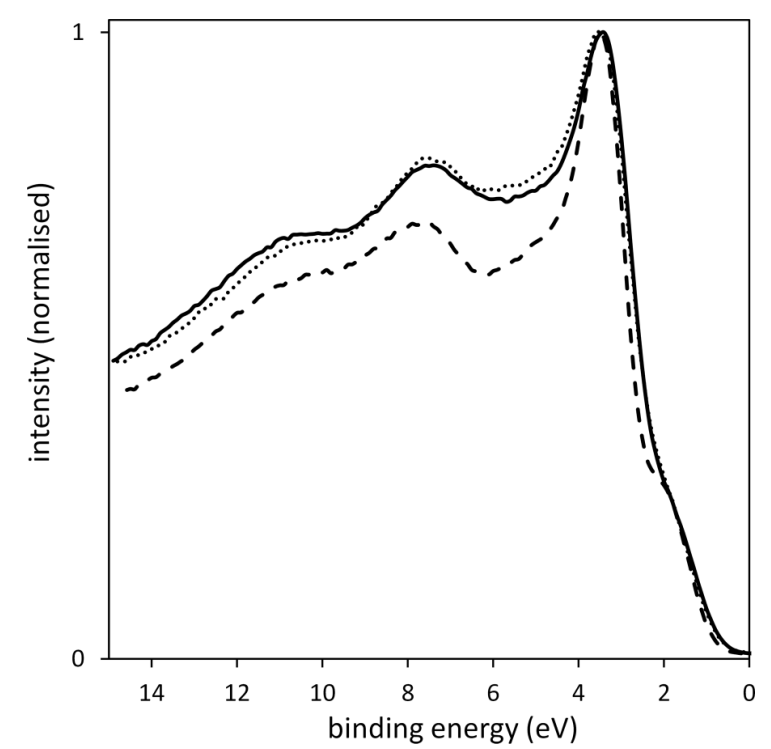

FIG. 8. $\mathrm{Mn} \mathrm{L}_{3}$-edge resonant photoemission spectra of (-- ) $\left(\mathrm{La}_{0.8} \mathrm{Sr}_{0.2}\right)_{0.98} \mathrm{MnO}_{3}$ at $25^{\circ} \mathrm{C},(-)\left(\mathrm{La}_{0.8} \mathrm{Sr}_{0.2}\right)_{0.98} \mathrm{MnO}_{3}$ at $300{ }^{\circ} \mathrm{C}$, and $(\bullet \bullet \bullet)$ $\left(\mathrm{La}_{0.8} \mathrm{Sr}_{0.2}\right)_{0.98} \mathrm{Mn}_{0.9} \mathrm{Cr}_{0.1} \mathrm{O}_{3}$ at $300{ }^{\circ} \mathrm{C}$. Incident photon energy $=643.5 \mathrm{eV}$.

Accordingly, heating of $\left(\mathrm{La}_{0.8} \mathrm{Sr}_{0.2}\right)_{0.98} \mathrm{MnO}_{3}$ resulted in an increase in the $(\mathrm{C}+\mathrm{D}) /\left(\mathrm{e}_{\mathrm{g}}+\mathrm{t}_{2 \mathrm{~g}}\right)$ ratio from $3.17 \pm 0.01$ to $3.73 \pm 0.02$, which is qualitatively consistent with the increase in electronic conductivity from $131 \mathrm{~S} \mathrm{~cm}^{-1}$ at room temperature to $174 \mathrm{~S} \mathrm{~cm}^{-1}$ at $850{ }^{\circ} \mathrm{C}$ for this material. In contrast to the overt effect of heating, the effect of lowlevel chromium substitution was not ascertainable by simple observation of Fig. 8. However, quantification of the extent of hybridisation revealed a decrease in the $(\mathrm{C}+\mathrm{D}) /\left(\mathrm{e}_{\mathrm{g}}+\mathrm{t}_{2 \mathrm{~g}}\right)$ ratio at elevated temperature from $3.73 \pm 0.02$ to $3.57 \pm 0.01$ upon low-level chromium substitution, indicative of lowered O 2p-Mn 3d hybridisation, and qualitatively consistent with the previously demonstrated lower electronic conductivity at $850{ }^{\circ} \mathrm{C}$ of $\left(\mathrm{La}_{0.8} \mathrm{Sr}_{0.2}\right)_{0.98} \mathrm{Mn}_{0.9} \mathrm{Cr}_{0.1} \mathrm{O}_{3}\left(89 \mathrm{~S} \mathrm{~cm}^{-1}\right)$ compared to $\left(\mathrm{La}_{0.8} \mathrm{Sr}_{0.2}\right)_{0.98} \mathrm{MnO}_{3}\left(174 \mathrm{~S} \mathrm{~cm}^{-1}\right){ }^{2}$

\section{CONCLUSIONS}

Soft X-ray synchrotron radiation was used for the first time to gain insight into the chromium poisoning of $(\mathrm{La}, \mathrm{Sr}) \mathrm{MnO}_{3^{-}}$ based SOFC cathodes. Changes in the electronic structure of ( $\mathrm{La}, \mathrm{Sr}) \mathrm{MnO}_{3}$ upon low-level chromium substitution were revealed, which were related to previously demonstrated decreases in electronic conductivity and electrochemical oxygen reduction activity. Thus, the results of this study provide an orbital-level understanding of the thermodynamically predicted SOFC cathode poisoning mechanism involving lowlevel chromium substitution on the $\mathrm{B}$-site of $(\mathrm{La}, \mathrm{Sr}) \mathrm{MnO}_{3}$.

\section{ACKNOWLEDGMENTS}

The authors thank the Swiss National Science Foundation (SNSF) Indo-Swiss Joint Research Programme for funding under Grant Agreement No. 138864 and are grateful for beamtime at ELETTRA under Proposal No. 20130288. F.B. was financially supported by the SNSF under Project No. 
137868. M.V. was supported by the Ministry of Education of the Czech Republic under Grant Nos. LM2011029 and LO1409. A.B. is grateful for financial support from the European Commission 7th Framework Programme project SOFC-Life (Solid Oxide Fuel Cells — Integrating Degradation Effects into Lifetime Prediction Models), Grant Agreement No. 256885.

${ }^{1}$ H. Yokokawa, T. Horita, N. Sakai, K. Yamaji, M. E. Brito, Y. P. Xiong, and H. Kishimoto, Solid State Ionics 177(35-36), 3193-3198 (2006).

${ }^{2}$ G. Tsekouras and A. Braun, Solid State Ionics 266, 19-24 (2014).

${ }^{3}$ R. Vašina, V. Kolařík, P. Doležel, M. Mynář, M. Vondráček, V. Cháb, J. Slezák, C. Comicioli, and K. C. Prince, Nucl. Instrum. Methods Phys. Res., Sect. A 467-468, 561-564 (2001).

${ }^{4}$ C. J. Powell and A. Jablonski, NIST Electron Inelastic-Mean-Free-Path Database, Version 1.2, SRD 71 (National Institute of Standards and Technology, Gaithersburg, MD, 2010).

${ }^{5} \mathrm{P}$. van der Heide, X-Ray Photoelectron Spectroscopy: An Introduction to Principles and Practices (Wiley, Hoboken, NJ, 2012).

${ }^{6}$ T. Ressler, J. Synchrotron Radiat. 5(2), 118-122 (1998).

${ }^{7}$ M. Wojdyr, J. Appl. Crystallogr. 43(5), 1126-1128 (2010).

${ }^{8}$ F. M. F. de Groot, M. Grioni, J. C. Fuggle, J. Ghijsen, G. A. Sawatzky, and H. Petersen, Phys. Rev. B 40(8), 5715-5723 (1989).

${ }^{9}$ M. Abbate, F. M. F. de Groot, J. C. Fuggle, A. Fujimori, O. Strebel, F. Lopez, M. Domke, G. Kaindl, G. A. Sawatzky, M. Takano, Y. Takeda, H. Eisaki, and S. Uchida, Phys. Rev. B 46(8), 4511-4519 (1992).

${ }^{10}$ D. D. Sarma, O. Rader, T. Kachel, A. Chainani, M. Mathew, K. Holldack, W. Gudat, and W. Eberhardt, Phys. Rev. B 49(20), 14238-14243 (1994).

${ }^{11}$ T. Caruso, C. Lenardi, R. G. Agostino, M. Amati, G. Bongiorno, T. Mazza, A. Policicchio, V. Formoso, E. Maccallini, E. Colavita, G. Chiarello, P. Finetti, F. Šutara, T. Skála, P. Piseri, K. C. Prince, and P. Milani, J. Chem. Phys. 128(9), 094704 (2008).
${ }^{12}$ M. Pedio, J. C. Fuggle, J. Somers, E. Umbach, J. Haase, T. Lindner, U. Hoefer, M. Grioni, F. M. F. de Groot, B. Hillert, L. Becker, and A. Robinson, Phys. Rev. B 40(11), 7924-7927 (1989).

${ }^{13}$ Z. Cai, Y. Kuru, J. W. Han, Y. Chen, and B. Yildiz, J. Am. Chem. Soc. 133, 17696-17704 (2011).

${ }^{14}$ Y. Chen, W. C. Jung, Y. Kuru, H. Tuller, and B. Yildiz, ECS Trans. 35, 2409-2416 (2011).

${ }^{15}$ J. W. Han, H. Jalili, Y. Kuru, Z. Cai, and B. Yildiz, ECS Trans. 35, 2097-2104 (2011).

${ }^{16}$ J. A. M. van Roosmalen, J. P. P. Huijsmans, and L. Plomp, Solid State Ionics 66(3-4), 279-284 (1993).

${ }^{17}$ S. P. Cramer, F. M. F. DeGroot, Y. Ma, C. T. Chen, F. Sette, C. A. Kipke, D. M. Eichhorn, M. K. Chan, and W. H. Armstrong, J. Am. Chem. Soc. 113(21), 7937-7940 (1991).

${ }^{18}$ T. Saitoh, A. E. Bocquet, T. Mizokawa, H. Namatame, A. Fujimori, M. Abbate, Y. Takeda, and M. Takano, Phys. Rev. B 51, 13942-13951 (1995).

${ }^{19}$ S. Kobayashi, T. Usui, H. Ikuta, Y. Uchimoto, and M. Wakihara, J. Mater. Res. 19(08), 2421-2427 (2004).

${ }^{20}$ J. S. Park, Y. P. Lee, and Y.-S. Lee, J. Appl. Phys. 101(9), 09G512 (2007).

${ }^{21}$ W. C. Jung and H. Tuller, Adv. Energy Mater. 1(6), 1184-1191 (2011).

${ }^{22}$ C. Zhang, C.-J. Li, G. Zhang, X.-J. Ning, C.-X. Li, H. Liao, and C. Coddet, Mater. Sci. Eng. 137(1-3), 24-30 (2007).

${ }^{23}$ C. Zener, Phys. Rev. 82(3), 403-405 (1951).

${ }^{24}$ H. Kumigashira, K. Horiba, H. Ohguchi, D. Kobayashi, M. Oshima, N. Nakagawa, T. Ohnishi, M. Lippmaa, K. Ono, M. Kawasaki, and H. Koinuma, J. Electron Spectrosc. Relat. Phenom. 136(1-2), 31-36 (2004).

${ }^{25}$ H. Wadati, D. Kobayashi, A. Chikamatsu, R. Hashimoto, M. Takizawa, K. Horiba, H. Kumigashira, T. Mizokawa, A. Fujimori, M. Oshima, M. Lippmaa, M. Kawasaki, and H. Koinuma, J. Electron Spectrosc. Relat. Phenom. 144-147, 877-880 (2005).

${ }^{26}$ L. F. J. Piper, A. R. H. Preston, S.-W. Cho, A. DeMasi, B. Chen, J. Laverock, K. E. Smith, L. J. Miara, J. N. Davis, S. N. Basu, U. Pal, S. Gopalan, L. Saraf, T. Kaspar, A. Y. Matsuura, P.-A. Glans, and J.-H. Guo, J. Electrochem. Soc. 158(2), B99-B105 (2011). 